$$
\text { CONF-960994--16 }
$$

Note: This is a preprint of a manuscript being prepared for publication. Contents of this paper should not be quoted or referred to without permission of the author(s).

(to be published in Nuc. Instr. and Meth.)

\title{
ION IMPLANTATION OF EPITAXIAL GaN FILMS: DAMAGE, DOPING AND ACTIVATION
}

\author{
Nalin Parikh. Agajan Suvkhanov, and Mike Lioubtchenko \\ Department of Physics and Astronomy \\ University of North Carolina, Chapel Hill, NC 27599-3255
}

9500473

Eric Carlson, Michael Bremser, David Bray and Robert Davis

Department of Materials Science and Engineering

North Carolina State University, Raleigh, NC 27695-7907

\section{John Hunn}

Oak Ridge National Laboratory

Oak Ridge, Tennessee 37831-6376
"The submitted manuscript has been
authored by a contractor of the U.S.
Government under contract No.
DE-AC05-960R22464. Accordingly,
the U.S. Government retains a
nonexclusive, royalty-free license
to publish or reproduce the published
form of this contribution. or allow others
to do so, for U.S. Government purposes."

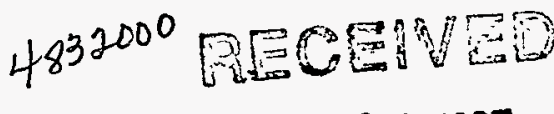

MAR 06 १997

Q.S.T I 


\section{DISCLAIMER}

Portions of this document may be illegible in electronic image products. Images are produced from the best available original document. 


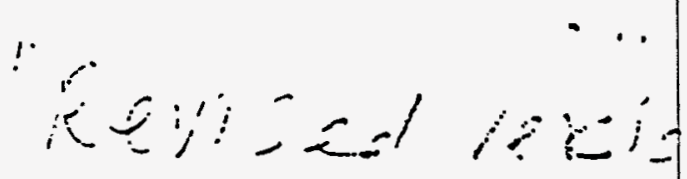

ION IMPLANTATION OF EPITAXIAL GaN FILMS: DAMAGE, DOPING AND ACTIVATION, Nalin Parikh, Agajan Suvkhanov, and Mike Lioubtchenko, Department of Physics and Astronomy, University of North Carolina, Chapel Hill, NC 27599-3255; Eric Carlson. Michael Bremser, David Bray and Robert Davis, Department of Materials Science and Engineering, North Carolina State Úniversity, Raleigh, NC 27695$79(17$ and John Hunn, Metals and Ceramics Division, Ouk Ridge National Laboratory, Oak Ridge, TN $37831-6.376$.

Monocrystalline GuN films grown on AIN buffer linyers previously deposited on $6 \mathrm{H}-$ $\mathrm{SiC}(()()() \mathrm{l})$ wafters and having dislocation densities on the order of 10$)^{7} \mathrm{~cm} / \mathrm{cm}^{3}$ beyond $(0.5$ $\mu \mathrm{m}$ from the initial growth intertace have been achieved via chemical vapor deposition (CVD). The absence of low angle grain boundaries invariably extant in GaN films deposited on sapphire substrates and the relatively low dislociation densities and absence of stacking faults and twinning in the implantation regions of the films make them the best materials available for the study of implantation doping.

In our initial study, 160 keV Si (n-type) and 120) keV Mg (p-type) with projected range $-110 \mathrm{~nm}$ and fluences of $1 \mathrm{e} 14,5 \mathrm{e} 14$ and $1 \mathrm{e} 15 \mathrm{~cm}^{-2}$ were implanted at both room temperature and $5500^{\circ} \mathrm{C}$. The samples were characterized by Rutherford backscattering (RBS)/channeling and photoluminescence (PL) techniques betore and after implantation. RBS/channeling results of virgin and as-implanted Gaiv for $120 \mathrm{keV} \mathrm{Mg}$ at $550^{\circ} \mathrm{C}$ and $1 \mathrm{el} \mathrm{cm}^{-2}$ fluence showed that even at this comparatively high dose the implantation damage is very little. However the characteristic PL signal which was present betore the implantation disappeared even for the lowest dose $\left(1 \mathrm{e} 14 \mathrm{~cm}^{-2}\right)$. These samples were annealed in a rapid themal annealing furnace at $1(K)()^{\circ} \mathrm{C}$, and damage recovery and dopant activation were measured by PL. RBS/channeling and Cross-Sectional TEM (XTEM). 


\section{INTRODUCTION:}

Recent successful fabrication of first blue-green ${ }^{l}$ and blue ${ }^{2}$ injection laser diodes (LD's), high-efficiency blue light-emitting diodes ${ }^{3}$ (LED's) and field effect transistors ${ }^{4}$ have generated a lot of interest in III-VI compound semiconductors particularly in GaN. One of the long-standing problems in GaN research has been how to introduce shallow ptype dopant. Most potential dopants have been observed to be compensated in GaN, yielding highly resistive materials. One of the limitations in the development of wide band gap semiconductors has been the difticulty in tinding suitable level dopants. Dopants may be introduced into semiconducting materials either during growth or by ion implantation. In planar device technology, ion implantation is a most promising doning technique for these materials because it allows the selective doping of certain regions and, therefore, the isolation of devices from each other. Ion implantation also offers advantages already known from silicon technology, including the introduction of nearly all elements of the periodic table and the precise control of dopant concentration and depth distribution. The major drawback of the technique is related to the lattice damage produced by the energetic ions. However, this damage can also be used beneficially as a gettering layer. For elemental semiconductors, lattice damage recovery via solid phase epitaxy has been successful; however, in a compound semiconductors native defects, e.g., antisite complexes, may be formed during the annealing which can compensate or trap charge carriers.

In early work Pankove and Hutchby 5.6 implanted 35 elements in GaN and measured photoluminescence spectra. Out of these elements $\mathrm{Zn}, \mathrm{Mg}, \mathrm{Cd}, \mathrm{C}, \mathrm{Li}$ and $\mathrm{Si}$ (in decreasing order) gave most elficient emission when implanted with relatively low doping concentration $\left(5 \times 10^{18}\right.$ atoms $\left./ \mathrm{cm}^{3}\right)$. Recently, Pearton et. al..$^{7}$ produced $\mathrm{n}$ - and $\mathrm{p}$-type conduction in $\mathrm{GaN}$ by implanting $\mathrm{Si}$ and $\mathrm{Mg} / \mathrm{P}$ respectively. $\mathrm{Mg}$ implantation alone did not produce p-type conduction but when co-implanted with $P$ produced $n-t o-p$ conversion after annealing at $1050-11000^{\circ} \mathrm{C}$. The p-type conduction was determined by the sign of the Hall effect and thermal probe measurements. The authors determined that only $62 \%$ of $\mathrm{Mg}$ ions were activated. The effect of co-implantation was to increase $\mathrm{Mg}$ substitution on Ga sites relative to $\mathrm{N}$ sites, presumably by filling up $\mathrm{N}$ vacancies with the $\mathrm{P}$ atoms. The quality of these devices needs improvement to make them commercially acceptable. This can be -achieved by optimizing implantation and annealing conditions. In this work we have -attempted to address this issue by implanting potential dopants Si and Mg in epitaxial GaiN samples. 


\section{EXPERIMENTAL:}

As-received vicinal $6 \mathrm{H}-\mathrm{SiC}(0)(0) 1)$ wafers oriented $3^{\circ}-4^{\circ}$ off-axis toward $\langle 1 \mid \overline{2}()\rangle$ were cut into $7 \mathrm{~mm}$ squares. These pieces were degreased in sequential ultrasonic baths of trichloroethylene, acetone and methanol and rinsed in deionized water. The $\mathrm{SiC}$ substrates were then dipped into a $10 \%$ HF solution for 10 minutes to remove the thermally grown oxide layer and blown dried with $\mathrm{N}_{2}$ betore being loaded onto a SiC-coated graphite susceptor contained in a cold-wall, vertical, pancike-style, OMVPE deposition system. The system was evacuated to less than $3 \times 10^{-5}$ Tort prior to initiating growth. The continuously rotating susceptor was RF inductively heated to the AlN deposition temperature of 110()$^{\circ} \mathrm{C}$ (optically measured on the susceptor) in 3 SLM of flowing $\mathrm{H}_{2}$ diluent. Hydrogen was also used as the carrier gas for the various metalorganic precursors. Deposition of AlN was initiated by flowing triechylaluminum (TEA) and ammonia ( $\mathrm{NH}_{3}$ ) into the reactor at $23.6 \mu \mathrm{mol} / \mathrm{min}$ and $1.5 \mathrm{SLM}$, respectively. The system pressure was 45 Torr. Each AlN buffer layer was grown for 30) minutes resulting in a thickness of $\sim 100) \mathrm{nm}$. The TEA flow was subsequently terminated, the substrate temperature decreased to 950$)^{\circ} \mathrm{C}$ and the system pressure increased to 90) Torr for GaN growth. The flow rate of triethylgallium (TEG) was maintained at $24.8 \mu \mathrm{mol} / \mathrm{min}$. The growth rate for GaN was $=10.9 \mu \mathrm{m} / \mathrm{hr}$. These films had a background carrier concentration of less than $1 \mathrm{e} 16 \mathrm{~cm}^{-3}$ as measured by capacitance-voltage. Details of the growth process and resulting films parameters are discussed elsewheres. As deposited films were characterized by $\mathrm{RBS} / \mathrm{channeling}$ with $1.6 \mathrm{MeV} \mathrm{He}{ }^{+}$with scattering angle at $165^{\circ}$, and photoluminescence (PL) at low temperature $(20 \mathrm{~K})$ in UHV ambient

After as-deposited films were characterized, the samples were implanted with 120) $\mathrm{keV} \mathrm{Mg}^{+}$, and $160 \mathrm{keV} \mathrm{Si}+$ with fluences of $1 \mathrm{el}, 5 \mathrm{el}$ and $1 \mathrm{e} 15 \mathrm{~cm}^{-2}$ at $550^{\circ} \mathrm{C}$ and room temperature. $\mathrm{Mg}$ and $\mathrm{Si}$ were selected because of their low ionization energies for ptype and n-type conversion of GaN. The energies of Mg and Si are calculated using IRIM code $^{9}$ to give an ion projected range of $110 \mathrm{~nm}$. As-implanted samples were again analyzed with RBS/channeling, C-V, PL, and XTEM. The cross-sectional TEM samples were made after implantation by cutting two pieces of the specimen and gluing them together face on. The samples were then ground down, polished, dimpled, and ion milled. The specimen was then imaged using a. TOPCON EMO)(12B electron microscope and a Philips -CM2())FEG. All cross-sectional images were taken in a $[11 \overline{2}()]$ orientation.

- After this the samples were annealed at $100(1)^{\circ} \mathrm{C}$ in a Rapid Thermal Anneal (RTA) furnace in $\mathrm{Ar}$ ambient for $60 \mathrm{~s}$. During the annealing. the samples were covered by undoped GaiN so that the two surfaces remained in close proximity, thereby not letting any 
volatile component escupe from the surface. Afterward the RTA samples were again characterized by the above-mentioned techniques.

\section{RESULTS and DISCUSSION:}

The GaN films deposited were single crystalline with very smooth surfaces except for a few random pinholes possibly caused by incomplete coalescence, as observed in plan view SEM. The PL spectra of GaN (taken at 10, 20, 30 and 40 $\mathrm{K}$ ) shown in Fig.1 revealed an intense near-edge emission at $3.46 \mathrm{eV}$, which has been attributed 10 to an exciton bound to a neutral donor. The FWHM of this peak was $3 \mathrm{meV}$.

RBS/channeling study of as-deposited samples showed very good channeling along the $C$ axis of the GaiN. The $\chi_{\min }$ (ration of aligned to random yield near the surface) of asdeposited samples were below $3 \%$, indicating a very high quality of epitaxial film. Fig.2 shows RBS/channeling spectra of as-implanted GaN for 120$) \mathrm{keV} \mathrm{Mg}^{+}$at $550^{\circ} \mathrm{C}$ with fluences of $1 \mathrm{e} 14,5 \mathrm{e} 14$ and $1 \mathrm{e} 15 \mathrm{~cm}^{-2}$. The figure shows that even at le15, a comparatively high dose, the implantation damage (near channel \#34()) was very little. However the characteristic PL signal which was present before the implantation disappeared even for the lowest dose $\left(1 \mathrm{e} 14 \mathrm{~cm}^{-2}\right)$. The $160 \mathrm{keV} \mathrm{Si}^{+}$samples implanted at 55()$^{\circ} \mathrm{C}$ also showed a low damage, again even the smallest fluence ( $\left(1+14 \mathrm{~cm}^{-2}\right.$ ) was enough to extinguish the PL signal. The samples implanted at room temperature (120 keV Mg) of same fluences showed higher damage compared to samples implanted at $55\left(1^{\circ} \mathrm{C}\right.$ (Fig.3). This was expected since there is some dynamic annealing of the implantation damage that occurs during the implantation.

To recover the crystalline quality and activate the dopants, samples were annealed at $10(0) 0^{\circ} \mathrm{C}$ for $60 \mathrm{~s}$ in argon ambient. RBS/channeling study revealed that some damage is removed as shown in Fig.4 for $160 \mathrm{keV}$ Si implanted at $5500^{\circ} \mathrm{C}$ and annealed at 100()$^{\circ} \mathrm{C}$. Even the smallest fluence implanted sumples of $\mathrm{Mg}$ or Si after RTA at $10000^{\circ} \mathrm{C}$ did not show PL signal. It seems that implanting at higher temperature helps to minimize damage. However, unfortunately GuN can not be implanted much higher than 550$)^{\circ} \mathrm{C}$ since nitrogen will start escaping the film above this temperature. In this case, one needs to go to a higher annealing temperature and at the same time minimize damage by implanting in several small fluences and anneal in between.

The XTEM study of as-implanted samples (1e15 Si/ $/ \mathrm{cm}^{2}$ at 551$)^{\circ} \mathrm{C}$ ) showed small damage clusters extended to $-300 \mathrm{~nm}$, which is a much larger than projected range for

-these ions $(110 \mathrm{~nm})$ as shown in Fig.5. The exact nature of the damage cluster, however, could not be determined using high resolution TEM. 


\section{SUMMARY:}

Single crystalline GaN films grown on AIN buffer layers previously deposited on $6 \mathrm{H}-\mathrm{SiC}(()(K) 1)$ were studied for radiation damage and its recovery using RBS/channeling, PL and XTEM. The highest fluence of (le $\left.15 \mathrm{~cm}^{-2}\right) 11() \mathrm{keV} \mathrm{Mg}$ and $160 \mathrm{keV}$ Si produced little damage at an implantation temperature of 551$)^{\circ} \mathrm{C}$. The room temperature damage was higher for the same tluences compared to implantation done at 55()$^{\circ} \mathrm{C}$. The damage was partially annealed by RTA at $100(1)^{\circ} \mathrm{C}$, however, this was not enough to recover the PL signal even for the lowest tluence (1e14 $\mathrm{cm}^{-2}$ ). XTEM study of as-implanted samples revealed small clusters of defects extended beyond the projected range of the ions. To recover damage completely perhaps one needs to go either much higher RTA temperature and/or implant samples in is smaller fluence increment and anneal in between the implants to recover the damage.

\section{REFERENCES:}

[1] M.A. Hause, J. Qui, J.M. DePuydt, and H. Cheng. Appl. Phys. Lett. 59, 1272 (1991)

[2] H. Jeon, J. Ding, A.V. Nurmikko, W. Xie, D.C. Grillo, M. Kobayashi, R.L. Gunshor, G.C. Hui, and N. Otsukia, Appl Phys. Lett. 60, $2(1) 45$ (1992).

[3] W. Xie, D.C. Grillo, R.L. Gunshor, M. Kobayashi, M. Jeon, J, Ding, A.V. Nurmikk, G.C. Hua, and N. Otsuka, Appl. Phys. Lett. 60, 1999 (1992).

[4] J.C. Zolper, R.J. Shul, A.G. Baci, R.G. Wilson. S.J. Pearson, R.A. Stall, Appl, Phys. Lett. 68, 2273, (1996).

[5] J.I. Pankove and J.A. Hutchby, Appl. Phys. Lett. 24, 281 (1974).

[6] J.I. Pankove and J.A. Hutchby, J. Appl. Phys. 47, 5387 (1976).

[7] S.J. Pearton, C.B. Vartuli, J.C. Zulper, C. Yuan, and R.A. Stall, Appl.Phys. Lett. 67, 1435 (1995).

[8] T. W. Weeks,Jr., MD. Bremser, K. S. Alley, E. Curlson, W.G. Perry, and R.F. Divis, Appl. Phys. Lett. 67, 401 (1995).

[9] J.F. Ziegler, J.P. Biersack and U. Littmark, in 'The Stopping and Range of Ions in Matter', Vol. 1, Pergumon, New York, 1985.

fl(0) R. Dingle, D.D. Sell, S.E. Stokowski, and M. Ilegems. Phys. Rev. B4, 1211 $=(1971)$. 


\section{ACKNOWLEDGMENT:}

The authors would also like to acknowledge partial support of SURAORAU/ORNL 1995 and 1996 Summer Cooperative Research Program. Research is sponsored in part by the Division of Materials Science and the Office of Fusion Energy, US Department of Energy, under contract DE-AC05-960R22464 with Lockheed Martin Energy Research Corp. 


\section{Figure caption:}

Fig. 1 PL spectra of a typical GaN tilm at low temperatures (10, 20, 30) and 40 K) film.

Fig. $2 \mathrm{RBS} / \mathrm{channeling}$ spectra of $\mathrm{GaN}$ implanted at 55()$^{\circ} \mathrm{C}$ with $120 \mathrm{keV} \mathrm{Mg}+$ tluences of le14 (--A--), 5e14 (--ne--) and le15 (----) $\mathrm{cm}^{-2}$.

Fig. 3 RBS/channeling spectra of GuiN implanted with 120$) \mathrm{keV} \mathrm{Mg}^{+}$fluence of $5 e 14 \mathrm{~cm}^{-2}$ at room temperature (--O) and 550$)^{\circ} \mathrm{C}(--\mathbf{A}--)$.

Fig. 4 RBS/channeling spectra of GaiN implanted with $160 \mathrm{keV} \mathrm{Si}$ thuence of le $15 \mathrm{~cm}^{-2}$ at 550$)^{\circ} \mathrm{C}(---)$ and RTA annealed at $1(0)(1)^{\circ} \mathrm{C}$ for $60 \mathrm{~s}(--\mathbf{-}-)$.

Fig. 5 TEM micrograph of damaged layer of GaiN implanted with $110 \mathrm{keV}$ Si tluence of 1 e $15 \mathrm{~cm}^{-2}$ at $550^{\circ} \mathrm{C}$. 


\section{PL of a $3.7 \mu \mathrm{m} \mathrm{GaN}$ at $10,20,30$ and $40 \mathrm{~K}$}

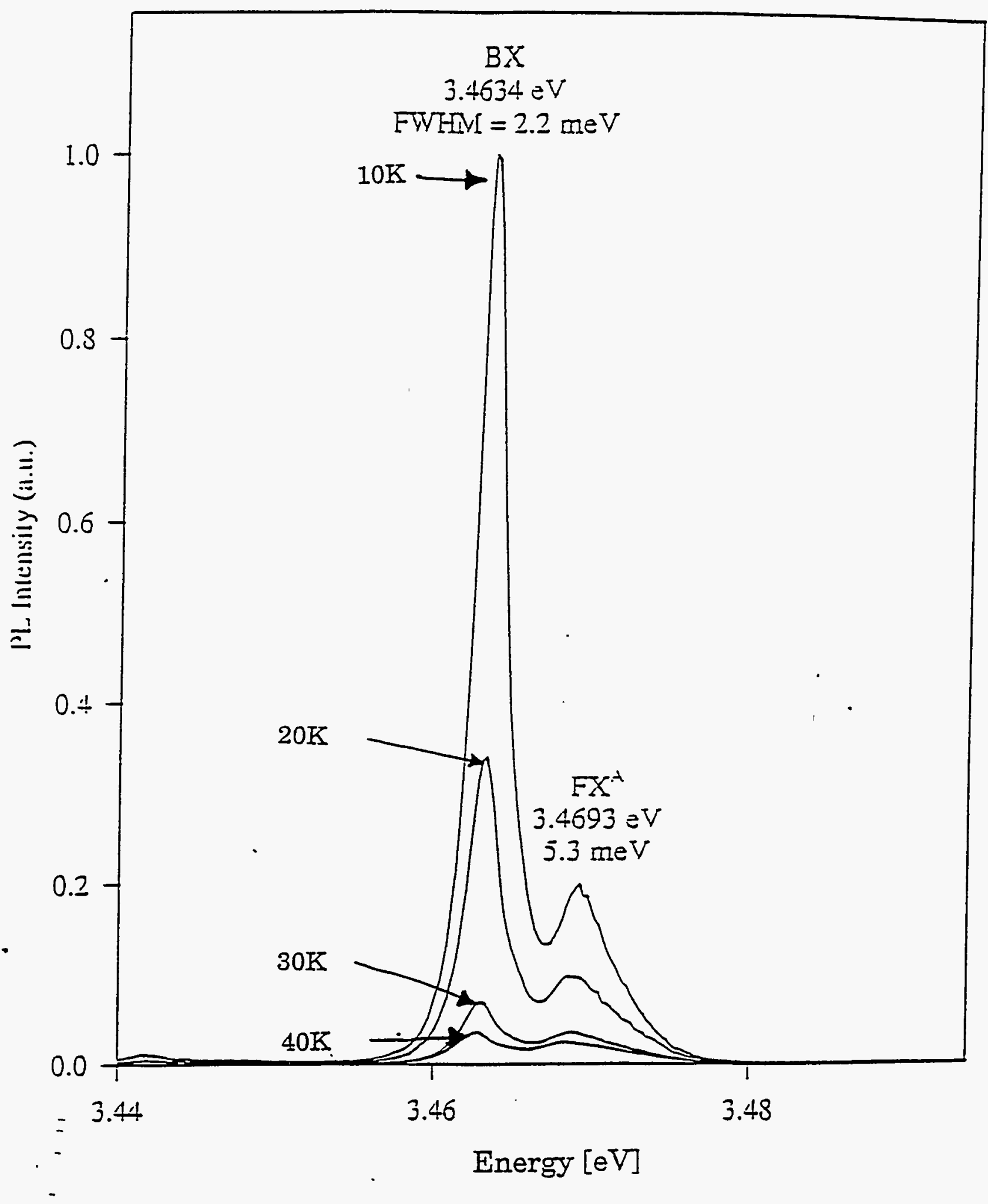

Fig. I 


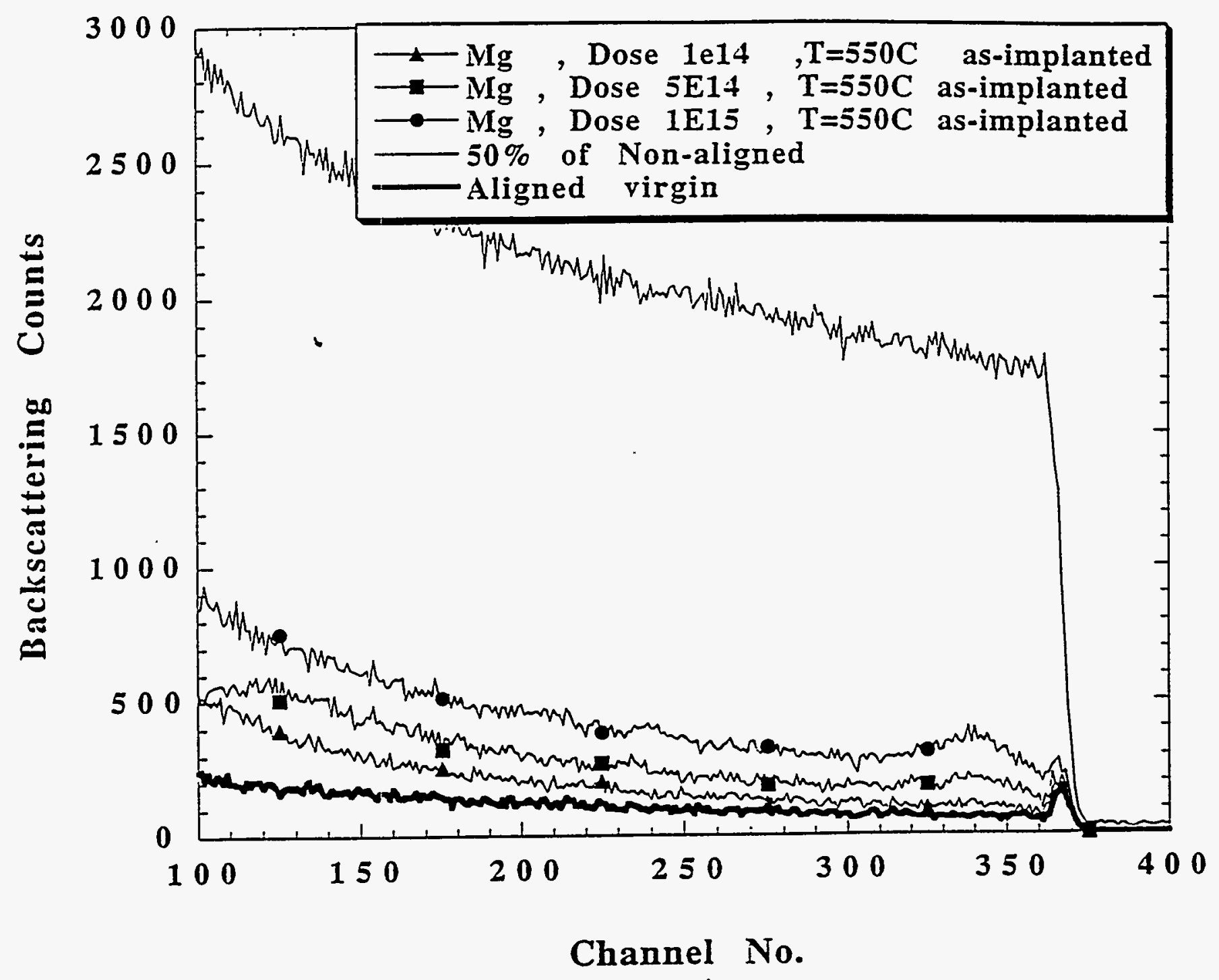

Fig. 2

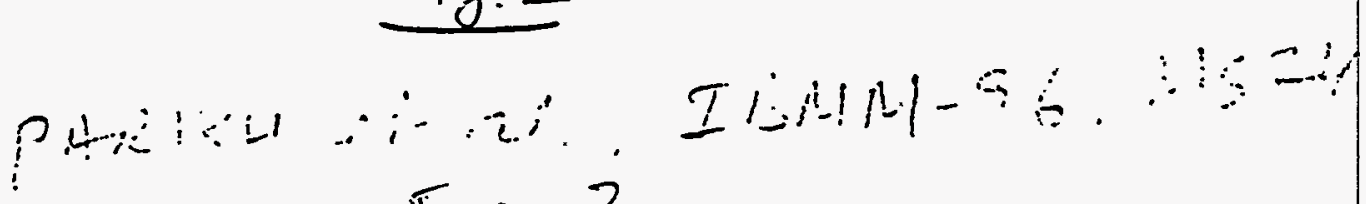
Fis. 


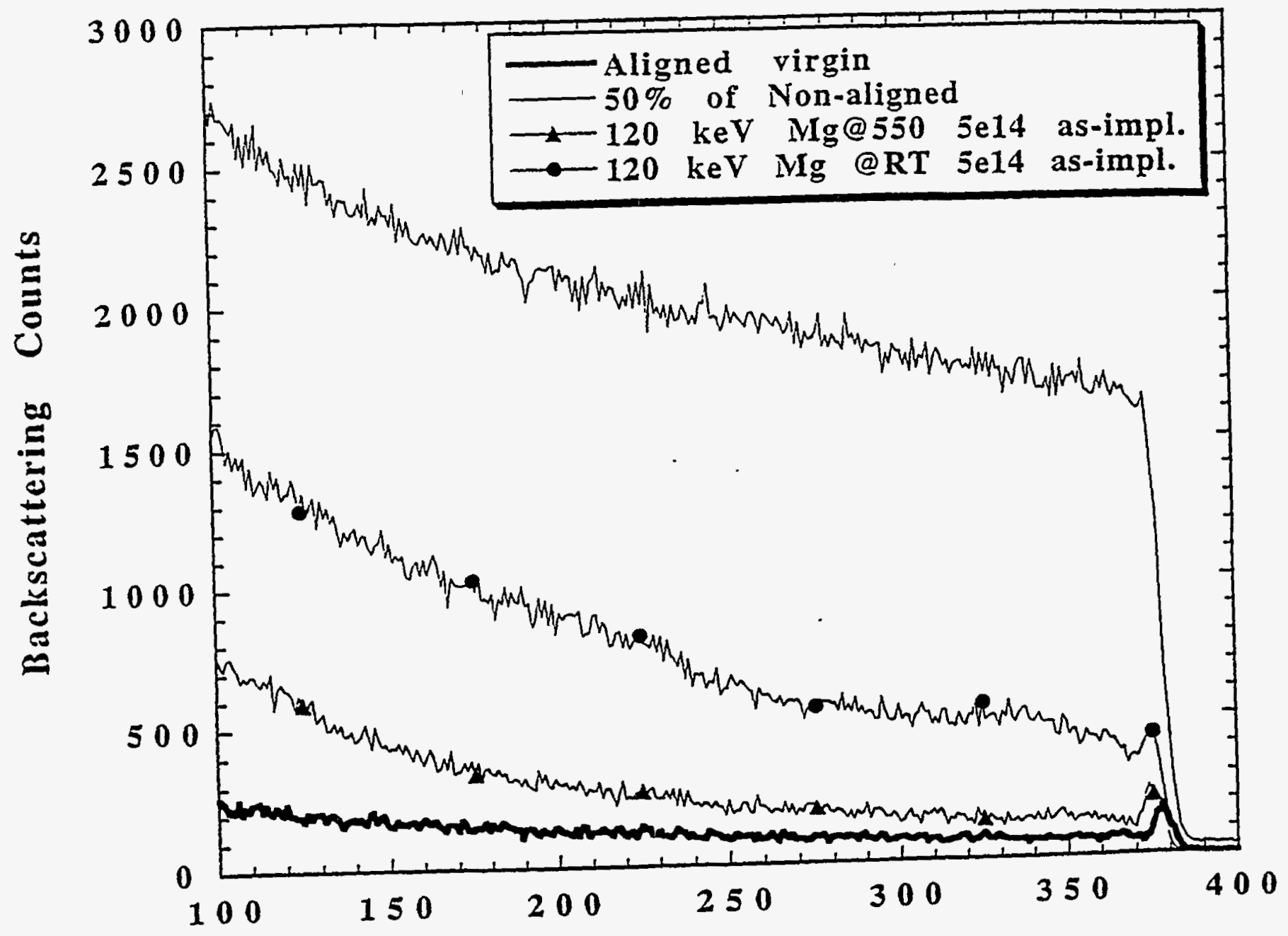

Channel No.

Fig. 3

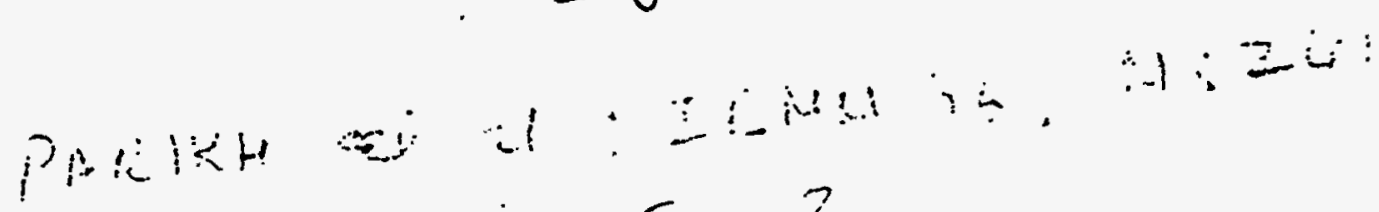
nt $?$ 


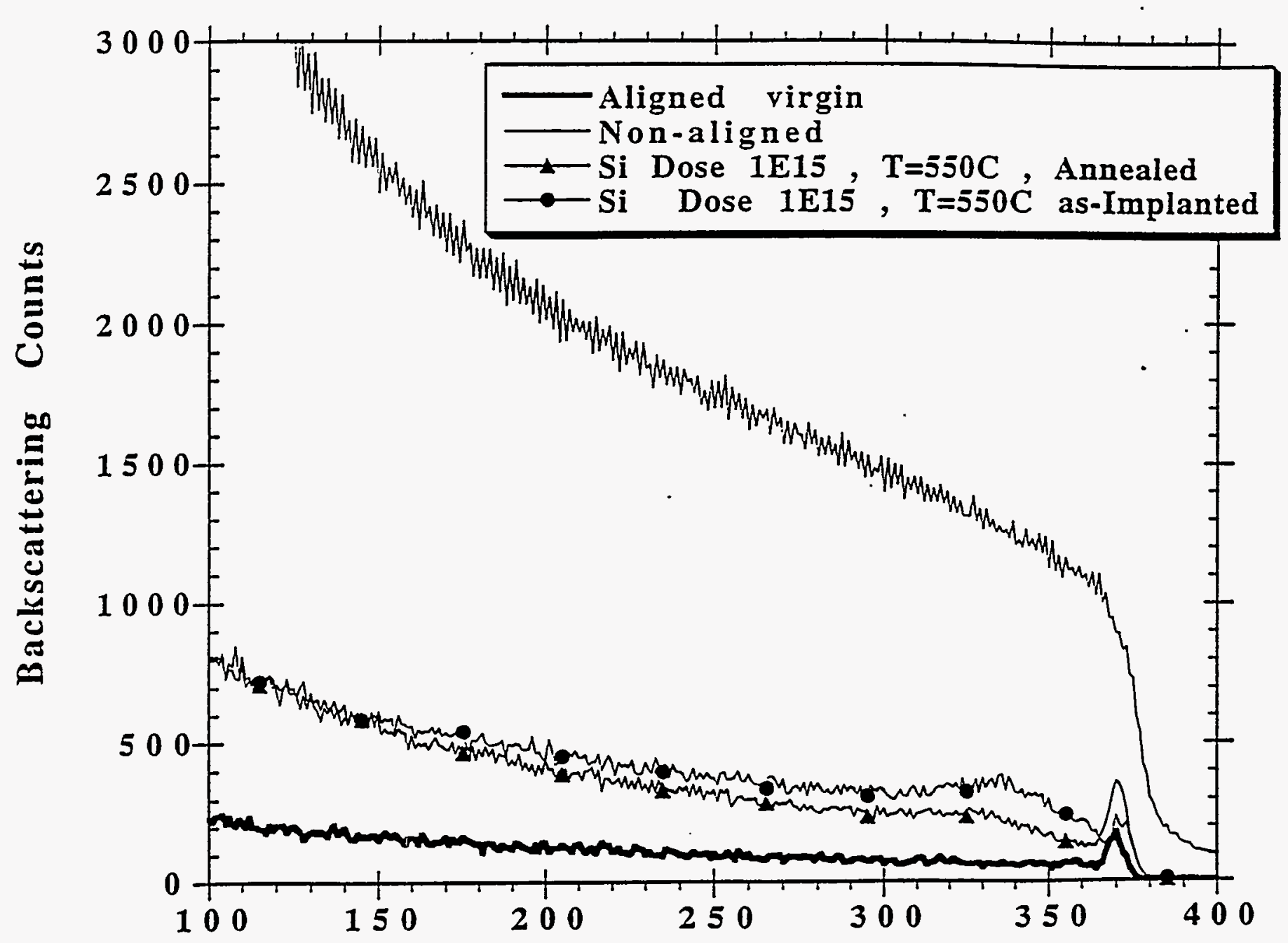

Channel No.

$=$

$$
\begin{aligned}
& \text { Fig. } 4 \\
& \text { PAlkH } \\
& 5.4
\end{aligned}
$$




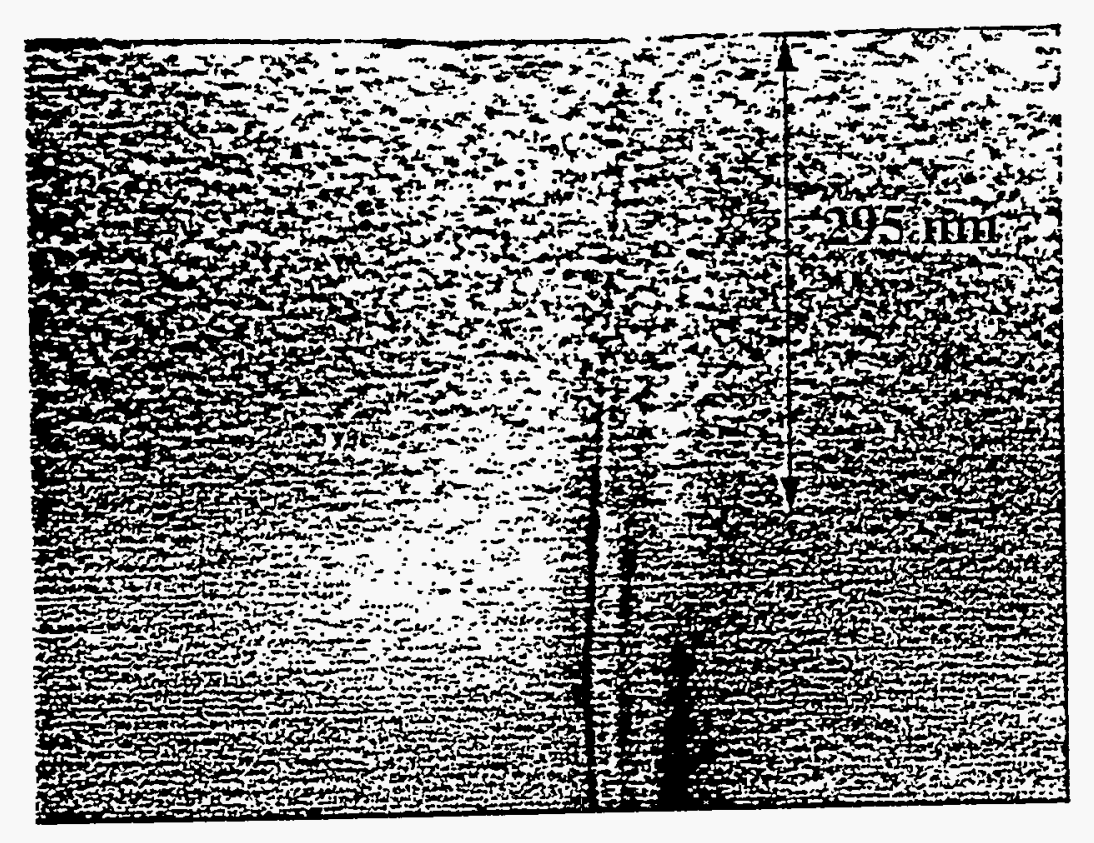

Fig. 5

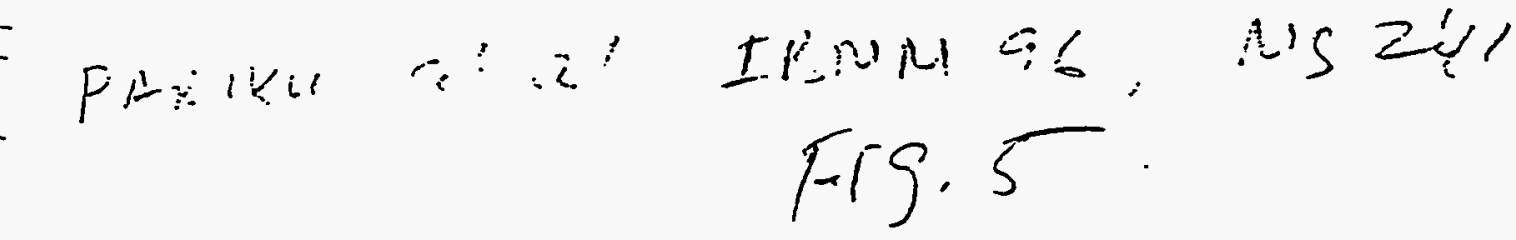

$$
\begin{aligned}
& 5:
\end{aligned}
$$

